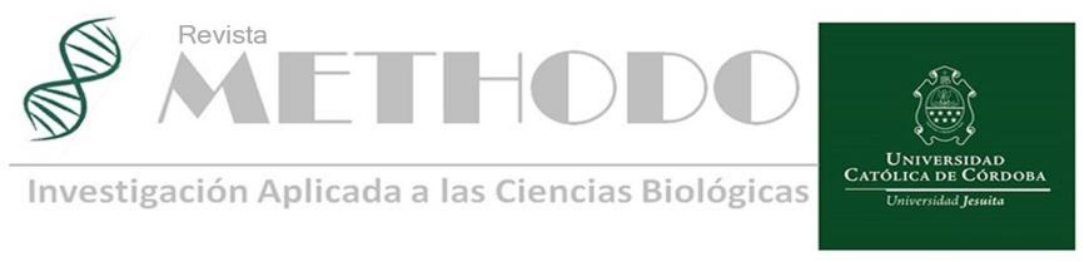

CASO CLINICO Rev. Methodo 2021;6(2):104-108 https://doi.org/10.22529/me.2021.6(2)08

Recibido 18 Nov. 2020 | Aceptado 18 Feb. 2021|Publicado 08 Abr 2021

\title{
Manifestación mucocutánea de toxicidad por dosis bajas de metotrexato, a propósito de un caso
}

\section{Mucocutaneous manifestation of low dose metotrexate toxicity, a purpose of a case}

\author{
Ana L. Gallmann ${ }^{1}$ (D) , Sofia C. Juarez ${ }^{1}$, Julieta R. Brusa ${ }^{1}$, María N. Andrade ${ }^{1}$, Anahí L Bringas ${ }^{1}$, René L \\ Panico $^{2}$, Gabriela Sambuelli ${ }^{3}$, Mariana B Papa ${ }^{1}$ \\ 1. Universidad Católica de Córdoba, Facultad de Ciencias de la Salud. Clínica Universitaria Reina Fabiola. Servicio de Dermatología \\ 2. Universidad Católica de Córdoba, Facultad de Ciencias de la Salud. Carrera de Odontología \\ 3. Universidad Católica de Córdoba, Facultad de Ciencias de la Salud. Clínica Universitaria Reina Fabiola. servicio de Anatomía Patológica \\ Correspondencia: Ana L. Gallmann Servicio de Medicina Interna. Clínica Universitaria Reina Fabiola, Córdoba, Argentina. E-mail: anagallmann@gmail.com.
}

\section{Resumen}

El metotrexato es un fármaco usado en el tratamiento de muchas enfermedades autoinmunes y auto inflamatorias. Sin embargo, ciertos eventos adversos se relacionaron con su administración, entre ellos la afectación mucocutánea.

Presentamos el caso de un paciente con manifestaciones de toxicidad dermatológica secundaria a la ingesta de metotrexato en forma diaria, sin indicación médica. Las lesiones respondieron a la suspensión de la droga y al tratamiento sintomático. El paciente no presentó compromiso sistémico severo.

Palabras clave: Metotrexato, mucositis, toxicidad.

\begin{abstract}
Methotrexate is a drug used in the treatment of many autoimmune and autoinflammatory diseases. However, certain adverse events have been related to its administration, including the mucocutaneous involvement.

We present the case of a patient with manifestations of dermatological toxicity secondary to the ingestion of methotrexate daily, without medical indication. The lesions responded to the suspension of the drug and symptomatic treatment. The patient did not present severe systemic compromise.
\end{abstract}

Keywords: Methotrexate, mucositis, toxicity.

\section{Introducción}

El metotrexato (MTX) es un antagonista del ácido fólico. A pesar del desarrollo de nuevos tratamientos biológicos específicos, éste sigue siendo el fármaco antirreumático de elección en el tratamiento de muchas enfermedades autoinmunes y autoinflamatorias debido a sus propiedades inmunomoduladoras y antiinflamatorias, gracias a su excelente relación eficacia-toxicidad-costo y a su esquema terapéutico sencillo ${ }^{1,2,3}$. Sin embargo, ciertos eventos adversos se relacionaron con su administración, entre ellos la afectación mucocutánea ${ }^{3}$.

Presentamos el caso de un paciente con manifestaciones de toxicidad dermatológica 
secundaria a la ingesta de MTX en forma diaria, sin indicación médica.

\section{Caso clínico}

Paciente de sexo masculino, de 74 años de edad, con antecedente de enfermedad pulmonar obstructiva crónica, tratado con bromuro de tiotropio inhalado, y coxalgia inespecífica para la cual se automedicó con $10 \mathrm{mg}$ de MTX por día durante diez días al mes por tres meses.

El paciente consultó al Servicio de Estomatología por presentar lesiones mucocutáneas dolorosas de aproximadamente una semana de evolución, por lo que se realizó biopsia de mucosa oral y se interconsultó al Servicio de Dermatología. Al examen físico dermatológico se evidenciaron erosiones extensas de base eritematosa y bordes irregulares, cubiertas por una membrana fibrinosa, localizadas en mucosa oral y genital (Figura. 1), y una lesión ampollar en mano derecha (Figura 2).

Ante la sospecha de toxicidad por MTX, eritema multiforme mayor, enfermedad ampollar autoinmune, liquen plano erosivo o ulceras de etiología infecciosa, se solicitó un estudio de laboratorio que informó un aumento de transaminasas -glutámico oxalacética transaminasa (GOT) $185 \mathrm{U} / \mathrm{L}$, glutamato-piruvato transaminasa (GPT) $170 \mathrm{U} / \mathrm{L}-\mathrm{y}$ trombopenia leve (plaquetas 128000/uL). No se observaron alteraciones en otras líneas celulares y la función renal y hepática estuvieron conservadas. Se solicitaron serologías (Virus Herpes Simple 1 y 2 , Virus Epstein-Barr, Citomegalovirus, Coxsackie, Parvovirus B19, Hepatitis B y C, VIH y Mycoplasma Pneumoniae) las cuales fueron negativas.

El estudio histopatológico de la biopsia realizada previamente informó patrón liquenoide y vasculopático con inmunofluorescencia directa compatible con farmacodermia (Figura 3 y 4).

Teniendo en cuenta las manifestaciones clínicas, el antecedente de consumo de MTX con dosificación diaria y sin suplementación con ácido fólico, el resultado del estudio histopatológico y habiendo descartado otras causas de mucositis, se llegó al diagnóstico de toxicidad por MTX.

Se decidió suspender el fármaco y se indicó tratamiento con clobetasol crema $0,05 \%$ cada $12 \mathrm{hs}$ en la lesión de mano derecha, lavados con syndet ph3.5 a base de ácido láctico con posterior aplicación de mometasona crema $0,1 \%$ cada $12 \mathrm{hs}$ en región genital y clobetasol orobase $0,05 \%$ cada 8 hs en mucosa oral. Luego de dos semanas de tratamiento el paciente presentó completa resolución de las lesiones y normalización de los parámetros de laboratorio.

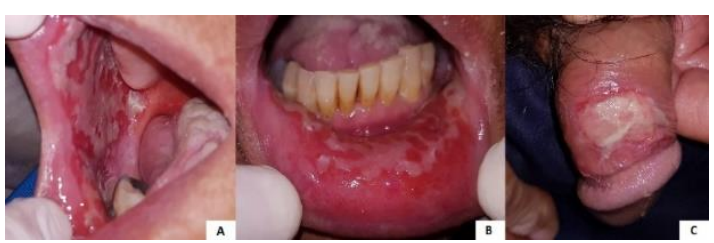

Figura1. Lesiones erosivas extensas de base eritematosa y bordes definidos, cubiertas por una membrana fibrinoide en mucosa vestibular (A), labio inferior (B) y dorso de pene (C).

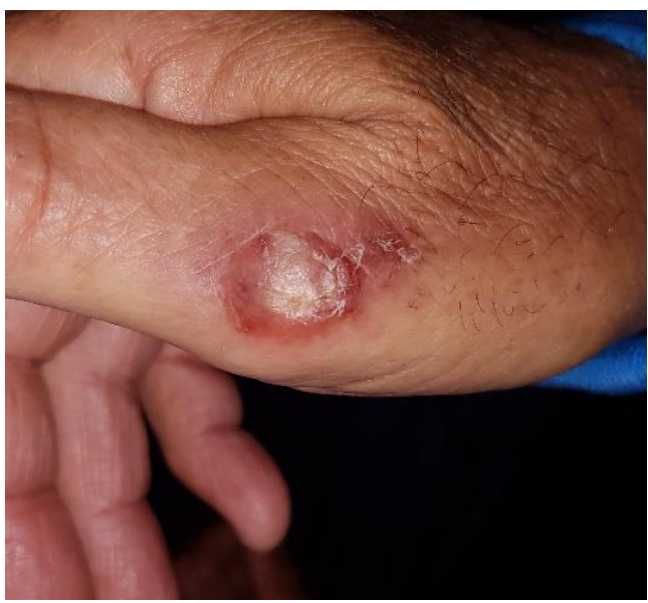

Figura 2. Lesión ampollar que asienta sobre base eritematosa en base de pulgar derecho.

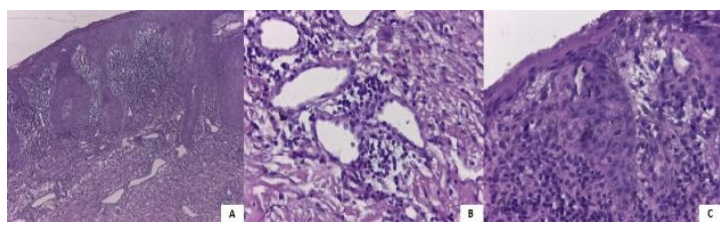

Figura 3. Microscopía óptica común, HematoxilinaEosina. 4x: Mucosa en la que se observa inflamación densa subepitelial (patrón liquenoide) (A). 40x: Infiltrado inflamatorio perivascular (B). 40x: Infiltrado liquenoide subepitelial con cuerpos de Civatte (C).

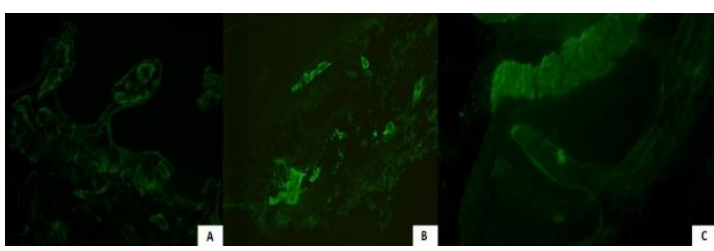

Figura 4. IFD: Depósito de Fibrinógeno en membrana basal y en paredes vasculares del corion subepitelial (A). Fracción de complemento $\mathrm{C} 3$ en paredes vasculares (B). IgM positiva en aislados cuerpos de Civatte (C): patrón liquenoide y vasculopático compatible con farmacodermia.

\section{Discusión}

MTX, sintetizado originalmente en la década de 1940 para el tratamiento de neoplasias malignas, es actualmente el fármaco modificador de la enfermedad de primera línea en el tratamiento de enfermedades como psoriasis y artritis reumatoide, entre otras, debido a sus propiedades

Revista Methodo: Investigación Aplicada a las Ciencias Biológicas. Universidad Católica de Córdoba. Jacinto Ríos 571 Bo Gral. Paz. X5004FXS. Córdoba. Argentina. Tel.: (54) 3514517299 / Correo: methodo@ucc.edu.ar / Web: methodo.ucc.edu.ar | CASO CLINICO Rev. Methodo 2021;6(2):104-108. 
antiinflamatorias e inmunomoduladoras ${ }^{1}$. MTX es un metabolito que interfiere con el metabolismo del ácido fólico uniéndose a la enzima dihidrofolatoreductasa (DHFR) con alta afinidad, inhibiendo competitivamente su acción para convertir dihidrofolato a tetrahidrofolato. Este último es esencial para la biosíntesis de purinas y pirimidinas, necesarias para la síntesis de ADN y la proliferación celular. De esta manera, interfiere con la capacidad de las células para dividirse y producir proteínas, e induce la muerte celular ${ }^{4,5}$.

Se sabe que las dosis altas de MTX (superiores a $500 \mathrm{mg} / \mathrm{m} 2$ ) usadas en enfermedades malignas, interfieren con la síntesis de ADN y ARN en células cancerígenas que se dividen rápidamente. Sin embargo, los mecanismos por los cuales las dosis bajas ejercen su efecto en los trastornos inflamatorios no están del todo claros. Se estima que la acción modificadora de la enfermedad es el resultado de una combinación de mecanismos que conducen a una atenuación de la respuesta inflamatoria, como la inhibición de la proliferación de los linfocitos u otras células inflamatorias, la supresión de la inflamación mediada por adenosina, la generación de especies reactivas del oxígeno y la alteración de la producción de metaloproteinasas de la matriz, prostaglandina E2 y citocinas ${ }^{1,2,6}$.

Las dosis bajas de MTX se administran por vía oral o subcutánea cada 7 días, y la dosis varía entre 7,5 y $25 \mathrm{mg}$ por semana ${ }^{1,4,7}$. Para los pacientes que están en tratamiento crónico con dosis bajas de MTX se recomienda la complementación con ácido fólico, pudiendo indicarse 1 a $5 \mathrm{mg}$ todos los días o una dosis única de $5 \mathrm{mg}$ entre 12 y 48 horas después de la administración de MTX. Esta suplementación reduce los efectos secundarios gastrointestinales, hematológicos, hepatotóxicos, cutáneos y mucosos, y no está asociada con una reducción en la eficacia. Para pacientes en tratamiento con dosis altas se recomienda la suplementación con leucovorina, la cual suministra la forma activa del ácido fólico; su dosis debe ajustarse según los dosajes de MTX ${ }^{2,7}$.

A pesar de una relación costo/efectividad muy favorable, la toxicidad sigue siendo motivo de preocupación. Hay dos grandes subconjuntos de eventos adversos: efectos sintomáticos, pero raramente mortales y efectos potencialmente mortales1; ambos son más comunes después de dosis altas de MTX, sin embargo, también fueron informados después de dosis tan bajas como $10 \mathrm{mg}$ por vía oral $^{8}$. La toxicidad del MTX se ve favorecida por diversos factores (Tabla 1). La causa más común de toxicidad es la sobredosis accidental o una administración errónea ${ }^{6,8,9}$, como en el caso de nuestro paciente quien, además, carecía de indicación médica.
Tabla 1. Factores favorecedores de la toxicidad por metotrexato.

\begin{tabular}{|c|c|c|}
\hline \multirow{2}{*}{\multicolumn{3}{|c|}{ Sobredosificación por error en la posología indicada (diaria en vez de semanal) }} \\
\hline & & \\
\hline \multicolumn{3}{|c|}{ Presencia de infección ${ }^{9}$} \\
\hline \multicolumn{3}{|c|}{ Defíciencia de ácido fólico ${ }^{9}$} \\
\hline \multicolumn{3}{|c|}{ Hipoalbuminemia ${ }^{9}$} \\
\hline \multicolumn{3}{|c|}{ Insuficiencia renal ${ }^{9}$} \\
\hline \multicolumn{3}{|c|}{ Formación de tercer espacio: ascitis o derrame pleural ${ }^{1}$} \\
\hline \multicolumn{3}{|c|}{ Ingesta de alcohol ${ }^{9}$} \\
\hline \multicolumn{3}{|c|}{ Edad avanzada ${ }^{9}$} \\
\hline \multicolumn{3}{|c|}{ Inicio reciente de MTX o aumento de dosis ${ }^{9}$} \\
\hline \multirow[t]{3}{*}{ Fármacos $9,11,12$} & $\begin{array}{l}\text { Por disminución de la } \\
\text { eliminación renal }\end{array}$ & $\begin{array}{l}\text { Aminoglucósidos, } \\
\text { antiinflamatorios no esclosporina, } \\
\text { sulfonamidas, probenecid, salicilatos, } \\
\text { penicilina, colchicina, cisplatino e } \\
\text { inhibidores de la bomba de protones }\end{array}$ \\
\hline & $\begin{array}{l}\text { Por desplazamiento } \\
\text { de la unión a } \\
\text { proteinas plasmática }\end{array}$ & $\begin{array}{l}\text { Salicilatos, probenecid, sulfonamidas, } \\
\text { barbitúricos, fenitoina, retinoides, } \\
\text { sulfonilureas, tetraciclinas y diuréticos }\end{array}$ \\
\hline & $\begin{array}{lr}\text { Por } r \text { toxicidad } \\
\text { sinérgica, inhibiendo } \\
\text { la DHFR }\end{array}$ & Trimetroprima/sulfametoxazol \\
\hline
\end{tabular}

MTX, metotrexato. DHFR, Dihidrofolatoreductasa.

Las principales células afectadas son las de proliferación rápida como las del tejido hematopoyético, el epitelio mucocutáneo y el epitelio gastrointestinal ${ }^{3,4,9}$.

Las reacciones mucocutáneas por MTX se observan especialmente con dosis bajas y en ausencia de suplementación con ácido fólico ${ }^{3,7,10}$. Las más frecuentes son úlceras mucosas, erosiones en las placas de psoriasis o en piel previamente sana, caída o rarefacción del cabello, fotosensibilidad, eritema acral, eritema multiforme, urticaria y vasculitis ${ }^{7,8}$.

La mucositis, que puede afectar a todo el tracto gastrointestinal, es una complicación frecuente. $\mathrm{Su}$ prevalencia, incidencia y gravedad varían según la edad, dosis y administración de otros fármacos. Generalmente se presenta dentro de los primeros 7 días de la administración, antes del inicio de la pancitopenia, ya que la acumulación de MTX es mayor en las células epiteliales de la mucosa que en las células madre de la médula ósea ${ }^{6}$. El proceso comienza con el daño al tejido conectivo y a los vasos sanguíneos que se encuentran en la submucosa, con liberación de citocinas proinflamatorias y radicales libres de oxígeno que exacerban el daño vascular y conducen a un círculo vicioso que lleva a la destrucción del tejido por activación de $\operatorname{caspasas}^{3,4}$. Los síntomas varían desde dolor y malestar leve hasta xerostomía e imposibilidad de tolerar la ingesta de alimentos y líquidos. Los pacientes con mala higiene dental o periodontal tienen mayor riesgo de mucositis. La complicación más grave son las infecciones sobre agregadas $^{3}$.

La afectación cutánea generalmente aparece conjuntamente con la mucositis ${ }^{6}$. y precede o acompaña a la toxicidad hematológica ${ }^{7,11}$. En la fisiopatogenia se ve involucrada la toxicidad 
directa del fármaco en las células epiteliales ${ }^{6}$. Las úlceras cutáneas aparecen principalmente en las piernas, manos y pies ${ }^{10}$. La erosión de las placas psoriásicas es una manifestación cutánea rara de toxicidad y se ha descrito como un predictor para la pancitopenia inminente ${ }^{11}$. Por otra parte, puede presentarse una nodulosis inducida por MTX con la formación de nódulos subcutáneos correspondientes a acumulaciones de células gigantes multinucleadas ${ }^{1}$.

En presencia de lesiones mucocutáneas la histología mostrará signos del efecto tóxico directo sobre el epitelio, como células epiteliales edematizadas, con citoplasma y núcleos pálidos, células vacuoladas o disqueratósicas y necrosis epitelial $^{6,7,9}$.

La hepatotoxicidad es uno de los principales efectos adversos de MTX, llegando al $70 \%$ en los primeros 2 a 4 años de tratamiento $^{2}$, siendo más común en terapias crónicas con dosis bajas ${ }^{4}$. La citólisis, con la consiguiente elevación en las aminotransferasas es común. El riesgo de esteatosis, fibrosis y cirrosis hepática ocurren con poca frecuencia con dosis bajas ${ }^{1,7}$.

Los efectos secundarios gastrointestinales, presentes en el $20 \%$ al $70 \%$ de los pacientes, incluyen náuseas, vómitos, diarrea, malestar abdominal y anorexia ${ }^{2,7}$.

La toxicidad hematológica puede variar desde citopenias leves hasta pancitopenia potencialmente mortal ${ }^{7}$.

La toxicidad renal puede ser secundaria a la precipitación de MTX y sus metabolitos en los túbulos renales o al efecto tóxico directo del fármaco $^{2}$. La falla renal disminuye la eliminación del MTX, y la consecuente exposición a concentraciones tóxicas empeora aún más la función renal, exacerbando además los efectos adversos no renales ${ }^{3}$.

La toxicidad pulmonar puede ser aguda y temprana, correspondiente a una reacción inmune idiosincrásica en forma de neumonía inmunoalérgica, o tardía en forma de fibrosis pulmonar ${ }^{7,2}$. Los síntomas generales comprenden astenia, disminución de la libido, cefalea y mareos ${ }^{7}$.

La tasa de infecciones y la gravedad de éstas podrían aumentar debido a los efectos inmunosupresores del MTX a altas dosis ${ }^{2}$.

Existen informes de casos que relacionan MTX con diferentes tipos de neoplasias, principalmente linfomas asociados con el virus de Epstein-Barr, sin embargo, no hay evidencia sólida para confirmar su oncogenicidad ${ }^{2,7}$.

Aunque el riesgo de efectos secundarios es mayor durante los primeros seis meses de administración de MTX, el seguimiento a largo plazo es necesario ${ }^{2}$ e incluye controles analíticos de función hepática y renal, así como hemograma completo, prestando especial atención al aumento del volumen corpuscular medio, indicador precoz de toxicidad ${ }^{2,8}$

En cuanto al manejo de los pacientes en tratamiento con MTX, para la prevención de la mucositis, se recomienda el mantenimiento de una buena higiene bucal y de las prótesis dentales. La ingesta de alimentos debe ser lenta y la comida debe ser cortada en trozos pequeños, evitando los platos muy calientes, crujientes e irritantes ${ }^{3}$.

Ante la sospecha de intoxicación por MTX debe solicitarse hemograma completo con recuento de plaquetas, pruebas renales, ionograma, hepatograma y radiografía de tórax ${ }^{9}$.

La eficacia de las terapias de rescate en la toxicidad por dosis bajas de MTX no está clara. El tratamiento en casos leves, como el nuestro, suele ser de apoyo ${ }^{11}$ Ante la aparición de mucositis existen distintas modalidades terapéuticas como la administración de analgésicos sistémicos y tópicos y enjuagues bucales antiácidos. La administración de anestésicos tópicos puede aumentar las lesiones y la duración de la mucositis ${ }^{3}$. La mucositis no complicada es de alivio espontáneo, con reepitelización completa entre diez días y cuatro semanas luego de suspendido el fármaco. Sin embargo, a veces es necesario el tratamiento con ácido fólico ${ }^{3,7,11}$.

Con respecto a la hepatotoxicidad, si el aumento de las transaminasas es menor de dos veces el límite normal se recomienda continuar con MTX y hacer controles de laboratorio más frecuentes, si la elevación es de entre dos y tres veces el valor normal se recomienda disminuir la dosis y en caso de persistencia suspender la droga y solicitar asesoramiento con un hepatólogo ${ }^{11}$.

El tratamiento de la intoxicación grave por MTX incluye la suspensión del fármaco, administración de leucovorina, hidratación agresiva y alcalinización urinaria. El factor estimulante de colonias granulocíticas debe ser considerado en pacientes con neutropenia ${ }^{9,11}$. Para casos de toxicidad pulmonar que pone en riesgo la vida, se recomienda el uso de glucocorticoides ${ }^{2}$.

En conclusión, MTX es un fármaco muy útil en el tratamiento de una amplia gama de patologías, sin embargo, no está exento de efectos adversos. Teniendo en cuenta que la causa más común de intoxicación es la ingesta accidental diaria, el médico debe asegurarse de confirmar el pleno entendimiento por parte del paciente de la pauta de administración indicada y desaconsejarle la autoadministración de drogas. La identificación de los signos dermatológicos es de vital importancia para detectar la toxicidad en una etapa temprana, antes del desarrollo de pancitopenia.

Destacamos entonces, el valor del trabajo en equipo, la importancia de reconocer los signos clínicos de toxicidad por MTX para llegar a un diagnóstico temprano, la obligatoriedad de 
descartar compromiso sistémico ante la presencia de lesiones mucocutáneas y la necesidad de suspender la droga e iniciar el tratamiento lo antes posible.

\section{Bibliografía}

1. Bedoui Y, Guillot X, Sélambarom J, Guiraud P, Giry C, Jaffar-Bandjee MC, et al. Methotrexate an Old Drug with New Tricks. Int. J. Mol. Sci. 2019; 20: 5023.

2. Wang W, Zhou H, Liu L. Side effects of methotrexate therapy for rheumatoid arthritis: A systematic review, Eur. J. Med. Chem. 2018; 158 (5): 502-516.

3. Esquivel-Pedraza L, Fernández-Cuevas L, Sánchez-Jiménez YM, Domínguez-Cherit J, Méndez-Flores S. Lesiones de la mucosa bucal por administración de metotrexato en paciente con artritis reumatoide. Dermatol Rev Mex. 2017;61(6):492-499.

4. Howard SC, Mccormick J, Pui CH, Buddington RK, Harveyd RD. Preventing and Managing Toxicities of High-Dose Methotrexate. TheOncologist. 2016; 21:14711482.

5. Sramek M, Neradil J, Veselska R. Much more than you expected: The non-DHFR-mediated effects of methotrexate. Biochim Biophys. 2017; 1861: 499-503.

6. Rampon G, Henkin C, Jorge VM, Almeida Jr. HL. Methotrexate-induced mucositis with extra-mucosal involvement after acidental overdose. An Bras Dermatol. 2018;93(1):155156.
7. Beylot-Barrya M, Le Maitre M, Goujonc C. Méthotrexate. Ann Dermatol Venereol. 2019; $146(6,7)$ : 459-465.

8. Ahmadzadeh A, Zamani N, HassanianMoghaddam H, Hadeiy SK, Parhizgar P. Acute versus chronic methotrexate poisoning; a cross-sectional study. BMC Pharmacol Toxicol. 2019; 20: 39.

9. Ferrari B, Kogan N, Veira RC, Luna PC, Larralde M,Cuesta MG, et al. Manifestaciones mucocutáneas de intoxicación por metotrexato. MEDICINA (Buenos Aires). 2018; 78: 50-53.

10. Tonini G, Lamberti A, Guidi I, Cinotti E, Rubegni P. Mucocutaneous ulcers as forerunners of methotrexate toxicity. Dermatologic Therapy. 2019; 32:12823.

11. Shiver MB, Hall LA, Conner KB, Brown GE, Cheung WL, Wirges ML. Cutaneous erosions: a herald for impending pancytopenia in methotrexate toxicity. Dermatology Online Journal. 2014; 20(7): 5.

12. Dalkilic E, Coskun BN, Ya??z B, Tufan AN, Ermurat S, Pehlivan Y. Methotrexate intoxication: Beyond the adverse events. International Journal of Rheumatic Diseases 2018; 21: 1557-1562.

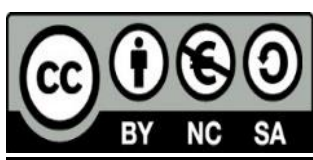

